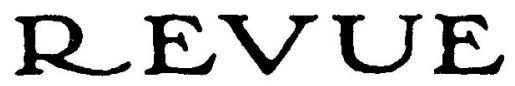

\title{
INTERNATIONALE DE LA
}
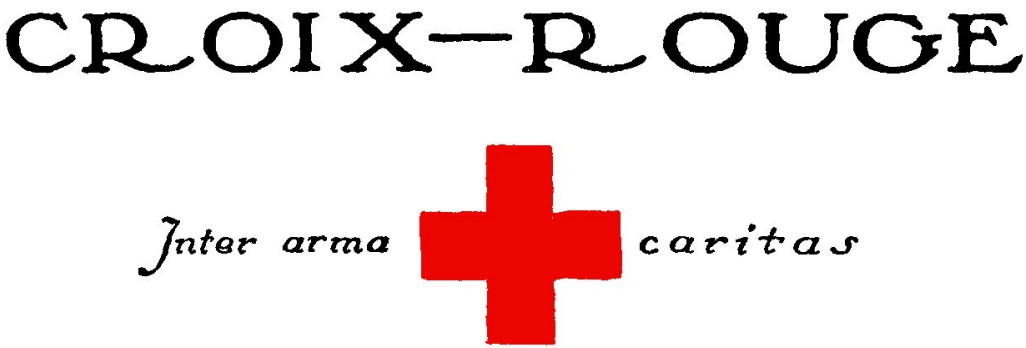

\section{BULLETIN INTERNATIONAL DES SOCIÉTÉS DE LA CROIX-ROUGE}

\author{
paraissant à la fin de chaque mois
}

T. LXX, No 445

\section{SOMMAIRE :}

LE COMITE INTERNATIONAL DE LA CIROIX-ROUGE ET LA GUERRE 719

NOTES ET DOCUMENTS : PROTEGTION DES POPULATIONS GIVILES:

Protocole concernant la prohibition d'emploi a la gucre de gaz asphyxiants,

toxiques ou similaires et de moyens bacteriologiques (Genève, 17 juin 1925),

726. - Liste des signataires du Protocole, 728 . - Notes officielles concernant l'observation des stipulations du Protocole, 729. - Limitation des bombardements aux objectifs militaires: Appel du Président des Etats-Unis d'Amériçue aux Gouvernements d'Allemagne, de France, de Grande-

Bretagne, d'Italie et de Pologne, 730. - Péponse du Chancelier du Reich

allemand, 731. - Réponse du Gouvernement britannique, 731. - Rêponse

du Gouvernement français, 732. - Réponse du Gouvernement polonais, 733. - Déclaration franco-britannique, 733. - Conclusion de l'allocution prononcée par $\mathrm{Sa}$ Sainteté le Souverain Pontife a l'occasion de la

remise des lettres de créance du nouvel ambassadeur de Belgique près le Saint-Siège, $73 \overline{5}$.

A Travers les REVUES. . . . . . . . . . . . . . . . 736

BULLETIN INTERNATIONAL DES SOCIETES DE LA CROIX-ROUGE

(Voir la 4 e page de la couverture). . . . . . . . . . . . . . . . . . 739

\section{GENĖVE}




\section{Comité international de la Croix-Rouge à Genève}

MM. Huber, Max, docteur en droit, ancien président de la Cour permanente de justice internationale, (1923), président.

Barbey-Ador, Frédéric, ancien ministre de Suisse en Belgique, (1915). Des Gouttes, Paul, docteur en droit, avocat, (1918).

Mme Ed. Frick-Cramer, (1918).

MM. Chenevière, Jacques, homme de lettres, (1919).

Logoz, Paul, docteur en droit, professeur de droit pénal à l'Université de Genève, colonel d'état-major général, (1921).

Motta, Giuseppe, docteur en droit, conseiller fédéral, (1923).

Mlle Ferrière, Suzanne, directrice-adjointe de l'International Migration. Service, (1924).

MM. de Haller, Rodolphe, banquier, (1924), trésorier.

Audeoud, G. E., Dr, colonel, ancien médecin de division de l'armée suisse, (1925).

Patry, Georges, $D^{r}$, colonel, ancien médecin de division, attaché à l'état-major de l'armée, (1929).

Mlle Odier, Lucie, ex-chef du Service des infirmières-visiteuses de la Croix-Rouge genevoise, (1930).

MM. de Planta, Franz, colonel, (1930).

Favre, Guillaume, colonel divisionnaire, (1932).

Zangger, Heinrich, $\mathrm{D}^{r}$ en médecine, professeur à l'Université et directeur de l'Institut de médecine légale de Zurich, (1932).

Burckhardt, Carl J., docteur en philosophie, haut commissaire de la Société des Nations à Dantzig, (1933).

Micheli, Jaeques-Barthélemy, ingénieur, (1935).

Wagniêre, Georges, docteur en droit, ancien ministre de Suisse à Rome, (1936).

Martin, Paul-E., docteur ès lettres, professeur d'histoire à l'Université de Genève, (1937).

Yung, Walter, docteur en droit, (1937).

Chapuisat, Edouard, docteur ès lettres, (1938).

M1le Bordier, Renée, infirmière chef au "Bon Secours ", (1938).

M. Cramer, Alee, Dr, colonel, (1938).

\section{Membres honoraires}

MM. Boissier, Edmond, colonel, (1914).

Bouvier, Bernard, professeur honoraire de 1'Université de Genève, (1919).

Cramer, Lucien, docteur en droit, (1921).

\section{Adresses des Comités centraux.}

AFRIQUE DU SUD. - Croix-Rouge sud-africaine, Red Cross House, 77, De Villiers Street, Johannesburg.

ALBANIE. - Croix-Rouge albanaise, Tirana.

ALLEMAGNE. - Croix-Rouge allemande, Präsidium, Potsdam-Babelsberg, 2, Berlin.

ARGENTINE. - Croix-Rouge argentine, Calle Juncal, 1635, Buenos-aires.

AUSTRALIE. - Croix-Rouge australienne, 42-46, Latrobe Street, Melbourne.

* BELGIQUE. - Croix-Rouge de Belgique, rue de Livourne, 80, Bruxelles.

BIRMANIE. - Croix-Rouge de Birmanie (Burma Red Cross Society), Rangoon.

BOLIVIE. - Croix-Rouge bolivienne, Casilla No 741, La Paz.

BRESIL. - Croix-Rouge brésilienne, Praça da Cruz Vermelha, 10-12, Rio de Janeiro.

BULGARIE. - Croix-Rouge bulgare, 21, boul. Totleben, Sofia.

CANADA. - Croix-Rouge canadienne, 621, Jarvis Street, Toronto 5.

CHILI. - Croix-Rouge chilienne, Calle Catedral, 1572, Santiago de Chile.

* Section: Croix-Rouge du Congo, rue de Livourne, 80, Bruxelles. 